\title{
Comunicação
}

[Communication $]$

\section{Pancreatite aguda necrótica em bugio-ruivo (Alouatta guariba clamitans) macho adulto}

\author{
[Necrotic acute pancreatitis in male adult Southern Brown Howler Monkey
}

(Alouatta guariba clamitans)]

\author{
S.D.E. Campos $^{1}$, R.A. Stadler ${ }^{2}$, C. Hennemann ${ }^{3}$, A. Polydoro ${ }^{3}$, R.V. Hohendorff ${ }^{4}$, \\ A.M. Pereira ${ }^{1}$, N.R.P. Almosny ${ }^{1}$
}

\author{
${ }^{1}$ Universidade Federal Fluminense - Niterói, RJ. \\ ${ }^{2}$ Escola Superior Batista do Amazonas - Manaus, AM \\ ${ }^{3}$ Laboratório de Patologia Clínica Veterinária C. Hennemann - Canoas, RS. \\ ${ }^{4}$ Fundação Zoobotânica do Rio Grande do Sul - Sapucaia do Sul, RS.
}

O bugio-ruivo (Alouatta guariba clamitans, Cabrera, 1940) habita o território brasileiro (Hirsch, 1988) e é um animal folívoro e frugívoro (Silva Júnior, 1981). A manutenção em cativeiro tem sido considerada difícil devido à má adaptação à dieta bem como à susceptibilidade a doenças (Breazile, 1987; Stuart et al., 1998).

A pancreatite é uma afecção inflamatória do pâncreas, frequentemente fatal, na qual ocorre a ativação intrapancreática de enzimas, iniciando um processo de autodigestão do tecido que agrava o processo inflamatório e pode evoluir para a forma hemorrágica e necrótica da doença associada à infecção (Andrade et al., 2002). Os mecanismos envolvidos na pancreatite não são totalmente elucidados. Acredita-se que existam causas tóxicas e metabólicas, além de refluxo duodenal, obstrução de ducto pancreático ou biliar, neoplasias, traumas e processos isquêmicos (Andrade et al., 2002). Os fatores nutricionais implicados em lesões nas células acinares incluem obesidade, dietas ricas em gorduras e hiperlipoproteinemia (Fraser et al., 1997).

O diagnóstico da pancreatite pode ser bastante difícil, pois os sinais clínicos nem sempre se mostram característicos (Thrall, 2004). Assim, tornam-se necessários testes laboratoriais, sendo que a avaliação das atividades séricas de amilase e lipase é a forma mais utilizada para o diagnóstico laboratorial da pancreatite no Brasil. A determinação dos valores de cálcio e proteínas séricas é considerada importante na complementação diagnóstica, tendo em vista o rápido decréscimo dessas durante a afecção (Thrall, 2004). O exame de tripsina imunorreativa, por ser espécie-específico, tem utilização limitada no país (Thrall, 2004).

Considerando-se a relevância clínica desta moléstia para onívoros e carnívoros, o objetivo deste trabalho foi relatar um caso de pancreatite aguda necrótica em um exemplar adulto macho de bugio-ruivo criado em cativeiro no Parque Zoológico da Fundação Zoobotânica do Rio Grande do Sul.

Em 3 de setembro de 2008, um exemplar macho de bugio-ruivo de nove anos de idade e criado em cativeiro, ao apresentar apatia e anorexia, foi encaminhado ao hospital veterinário e contido mecanicamente para a pesagem, exame físico e coleta de $5 \mathrm{~mL}$ de sangue da veia braquial, para a realização de hemograma e dosagens bioquímicas séricas e pesquisa de hemoparasitas. $\mathrm{O}$ exame físico inicial revelou baixo escore corporal, evidenciado pelo peso de $5,2 \mathrm{~kg}$ e marcante estado de apatia, embora não houvesse outras alterações significativas.

Recebido em 23 de abril de 2010

Aceito em 4 de outubro de 2010

E-mail: s.destri@gmail.com 
As amostras de sangue foram processadas no Laboratório Clínico Veterinário C. Hennemann. Um contador automático de células (Counter BE$2001^{\circledR}$ ) foi utilizado para a realização dos hemogramas. O volume globular foi determinado pelo método de micro-hematócrito. Os esfregaços sanguíneos foram corados com corante rápido para hematologia (Panótico, Instant $\left.\operatorname{Prov}^{\circledR}\right)$, e a leitura das lâminas foi realizada em objetiva de imersão. Para as dosagens bioquímicas séricas de ureia, creatinina, alanina aminotransferase (ALT), aspartato aminotransferase (AST), fosfatase alcalina (FA), amilase e creatino kinase (CK), utilizou-se aparelho semiautomático (Bioplus $200^{\circledR}$ ). Os resultados encontrados na hematologia e bioquímica foram comparados aos valores de normalidade citados por Santos (1999) e Teare (1999). Devido à dificuldade na obtenção de parâmetros de normalidade para a espécie em estudo, os valores para volume globular médio (VGM) e atividade sérica de lipase foram comparados à espécie Alouatta caraya (Teare, 1999).

Em 8 de setembro de 2008, sem melhora no quadro clínico, procedeu-se à contenção física para nova coleta de sangue. Foi instituída fluidoterapia no volume de $400 \mathrm{~mL}$ de solução fisiológica de cloreto de sódio $0,9 \%$ por via intravenosa (IV). Procedeu-se à administração intramuscular (IM) de $0,5 \mathrm{~mL}$ de antibiótico à base de benzilpenicilina benzatina, benzilpenicilina procaína, benzilpenicilina potássica, sulfato de di-idroestreptomicina e sulfato de estreptomicina correspondendo a $24.000 \mathrm{UI} / \mathrm{kg}$ das penicilinas e $10 \mathrm{mg} / \mathrm{kg}$ de estreptomicina e di-idroestreptomicina.

No dia 9 de setembro de 2008, apresentando-se em posição antiálgica compatível com dor abdominal, foi administrado antiespasmódico à base de N-butilbrometo de hioscina e dipirona sódica, na dose de $0,16 \mathrm{mg} / \mathrm{kg} \mathrm{IM}$, e protetor de mucosa gástrica à base de cloridrato de ranitidina, na dose de $0,5 \mathrm{mg} / \mathrm{kg}$ via oral (ambos calculados por estrapolação alométrica), além de hepatoprotetor à base de aspartato de L-ornitina (20mg/kg), cloridrato de L-arginina $(75 \mathrm{mg} / \mathrm{kg})$, L-citrulina $\quad(5 \mathrm{mg} / \mathrm{kg})$, acetil metionina $(10 \mathrm{mg} / \mathrm{kg})$, cloridrato de colina $(10 \mathrm{mg} / \mathrm{kg}) \mathrm{e}$ levulose $(100 \mathrm{mg} / \mathrm{kg})$ e fluidoterapia com solução fisiológica IV.

Em 10 de setembro de 2008, o animal foi contido fisicamente visando à repetição da terapêutica e à nova coleta de sangue para acompanhamento do perfil bioquímico e dosagem sérica de gama glutamil transferase (GGT) e lipase. O animal veio a óbito, decorrente de parada respiratória, e foi encaminhado para necropsia para se avaliar o aspecto macroscópico do tecido subcutâneo e as estruturas internas da cavidade abdominal.

Os resultados do perfil hematológico e bioquímico, referentes aos dias três, oito e 10 de setembro, encontram-se nas Tab. 1 e 2.

Tabela 1. Perfil hematológico do exemplar de bugio-ruivo (Alouatta guariba clamitans)

\begin{tabular}{|c|c|c|c|c|}
\hline Parâmetros & \multicolumn{2}{|c|}{ Exame $n^{0} 1$} & \multicolumn{2}{|c|}{ Exame $\mathrm{n}^{0} 2$} \\
\hline Hematimetria $\left(\times 10^{6} / \mu \mathrm{L}\right)$ & \multicolumn{2}{|c|}{5,03} & \multicolumn{2}{|c|}{4,62} \\
\hline Hemoglobina $(\mathrm{g} / \mathrm{dL})$ & \multicolumn{2}{|c|}{11,4} & \multicolumn{2}{|c|}{9,2} \\
\hline Volume globular (\%) & \multicolumn{2}{|c|}{33} & \multicolumn{2}{|c|}{30} \\
\hline Volume globular médio (fL) & \multicolumn{2}{|c|}{65,6} & \multicolumn{2}{|c|}{64,9} \\
\hline CHGM $(\%)$ & \multicolumn{2}{|c|}{34.5} & \multicolumn{2}{|c|}{30,7} \\
\hline Leucometria global $(/ \mu \mathrm{L})$ & \multicolumn{2}{|c|}{3.900} & \multicolumn{2}{|c|}{3.500} \\
\hline Leucometria específica & Relativa (\%) & Absoluta $(/ \mu \mathrm{L})$ & Relativa (\%) & Absoluta $(/ \mu \mathrm{L})$ \\
\hline Basófilos & 0 & 0 & 0 & 0 \\
\hline Eosinófilos & 2 & 78 & 0 & 0 \\
\hline Mielócitos & 0 & 0 & 0 & 0 \\
\hline Metamielócitos & 0 & 0 & 0 & 0 \\
\hline Bastonetes & 0 & 0 & 0 & 0 \\
\hline Segmentados & 47 & 1.833 & 86 & 3.010 \\
\hline Linfócitos & 36 & 1.404 & 10 & 350 \\
\hline Monócitos & 15 & 585 & 4 & 140 \\
\hline
\end{tabular}

CHGM: concentração de hemoglobina globular média. 
Tabela 2. Perfil bioquímico do exemplar de bugio-ruivo (Alouatta guariba clamitans)

\begin{tabular}{|c|c|c|c|}
\hline Parâmetros & Exame $\mathrm{n}^{\mathrm{o}} 1$ & Exame $\mathrm{n}^{\circ} 2$ & Exame $\mathrm{n}^{\mathrm{o}} 3$ \\
\hline Ureia (mg/dL) & 56,4 & 64,8 & - \\
\hline Creatinina $(\mathrm{mg} / \mathrm{dL})$ & 0,8 & 1,2 & - \\
\hline Alanina aminotransferase (UI/L) & 23,5 & 111,7 & 269,8 \\
\hline Aspartato aminotransferase (UI/L) & 223,5 & 144,0 & 151,8 \\
\hline Fosfatase alcalina (UI/L) & 168,9 & 87,8 & 133,2 \\
\hline Gama glutamil transferase (UI/L) & - & - & 8,6 \\
\hline Amilase (UI/L) & 1010,10 & $733, .3$ & 784,5 \\
\hline Lipase (UI/L) & - & - & 194,1 \\
\hline Creatino kinase (UI/L) & 153,8 & 2688,0 & 2070,0 \\
\hline
\end{tabular}

Os valores de volume globular estavam dentro dos parâmetros de normalidade, embora, na primeira coleta, o valor da hematimetria estivesse discretamente mais alto. Na pancreatite aguda, pode ocorrer aumento do hematócrito, hematimetria e hemoglobinometria por hemoconcentração resultante da desidratação induzida pelos vômitos e anorexia, com ingestão insuficiente de líquidos (Thrall, 2004). No segundo exame, a diminuição da hemoglobinometria caracterizou anemia, mesmo que discreta, com microcitose, evidenciada pelo baixo VGM. A destruição do tecido pancreático com hemorragia e necrose, que ocorre em casos agudos de pancreatite (Thrall, 2004), pode justificar essa discreta anemia, em que a hidratação do animal corrigiu a hemoconcentração, e houve diminuição do VG e hematimetria, embora dentro da normalidade, quando comparados ao primeiro exame.

Não foram encontrados hemoparasitas. Os neutrófilos segmentados de primatas são fagócitos e uma de suas funções mais importantes é a de destruir microrganismos, de modo que o aumento de neutrófilos circulantes pode ocorrer nas inflamações, principalmente de causa bacteriana (Thrall, 2004), diferente dos resultados deste estudo, que demonstraram leucopenia com neutropenia. A leucopenia decorrente de processos inflamatórios agudos ocorre frequentemente em septicemia quando não há um foco inflamatório/infeccioso definido e pode ser considerada de prognóstico desfavorável por indicar intensa quimiotaxia e mobilização de neutrófilos da circulação para o foco, e quando a velocidade de produção desses na medula é menor que a demanda para o combate à inflamação/infecção (Moore e Bender, 2000).

Neste caso, a grande destruição tecidual decorrente do vazamento de enzimas pancreáticas na cavidade, provavelmente, levou à intensa morte celular com liberação de quimiotáticos, estimulando a migração de neutrófilos. Já os monócitos, que apresentam atividade fagocítica, possuem substâncias químicas envolvidas na inflamação e destruição de organismos invasores, as quais são ativadas pela liberação de citocinas quimiotáticas (Carneiro e Siqueira-Batista, 2004), o que poderia justificar a monocitose evidenciada ao primeiro exame.

Os valores de creatinina mantiveram-se nos limites de normalidade, indicando provavelmente adequada função renal, embora os valores de ureia tenham permanecido acima do esperado. Foram observadas atividades elevadas de ALT, AST, CK, amilase e lipase e reduzida de GGT.

Embora as dosagens de ureia e creatinina sejam frequentemente utilizadas na avaliação da função renal, a creatinina tem se mostrado um parâmetro mais fidedigno, uma vez que existem causas extrarrenais que podem ter sido responsáveis pelo aumento da ureia sérica neste caso, como a desidratação e extenso catabolismo proteico devido à ação proteolítica das enzimas pancreáticas nos tecidos (Thrall, 2004).

O aumento da atividade sérica de enzimas hepáticas é comumente associado à pancreatite $\mathrm{e}$ causado pela lesão tóxica de hepatócitos secundária à liberação de enzimas pancreáticas (Thrall, 2004). A atividade elevada de AST é relatada em injúrias hepáticas de mamíferos e, embora seja um parâmetro menos específico nos processos iniciais de lesão hepatocelular do que a atividade sérica de ALT, pode indicar lesão hepática severa, pois seu vazamento depende de lesão mais grave (Thrall, 2004).

A atividade enzimática da FA mostrou-se elevada na primeira coleta. Tal alteração não foi 
considerada significativa, pois, nos demais exames, os valores retornaram aos limites fisiológicos adequados, tornando a hipótese de colestase improvável, juntamente com o resultado da atividade sérica de GGT, já que níveis baixos de GGT não apresentam importância clínica relevante. O aumento de CK pode ser explicado pela hipótese de que a liberação excessiva de tripsina atinge a musculatura em um processo de digestão enzimática entretanto, não se pode descartar o aumento na atividade muscular em razão dos procedimentos de captura e contenção (Thrall, 2004).

O provável diagnóstico de pancreatite aguda decorreu, por associação às demais alterações, do marcante grau de elevação na atividade da enzima pancreática amilase somado ao aumento na atividade sérica da enzima pancreática lipase solicitada ao terceiro exame, uma vez que lesão ou morte de células acinares pancreáticas resulta no extravasamento de amilase e lipase (Thrall, 2004).

O animal apresentava icterícia de mucosas oral e ocular e dispneia quando veio a óbito em 10 de setembro de 2008. Na necropsia, após o rebatimento da pele, observou-se que o tecido subcutâneo apresentava intensa coloração ictérica. À abertura da cavidade abdominal, foi evidenciada, ainda, icterícia em elevado grau na gordura perirrenal, no omento maior e no menor e no mesentério e, também, esplenomegalia e hepatomegalia, com fígado marrom-pálido e friável (Fig. 1A e 1B).

As mucosas gástrica e intestinal não demonstraram sinais de alterações. Os rins apresentavam coloração ictérica, e o pâncreas, disforme, com poucas áreas de tecido glandular e coloração característica de icterícia com focos necróticos (Fig. 1C). O animal apresentava ainda cardiomegalia de formato arredondado, com icterícia na parede dos grandes vasos e área de sufusão hemorrágica no miocárdio. O pâncreas lesado libera um fator tóxico do miocárdio, que, associado ao processo proteolítico da tripsina, auxilia na compreensão das alterações cardíacas evidenciadas à necropsia e contribui para justificar o excessivo aumento da atividade sérica de CK (Thrall, 2004). Os demais órgãos não apresentaram alterações dignas de nota.
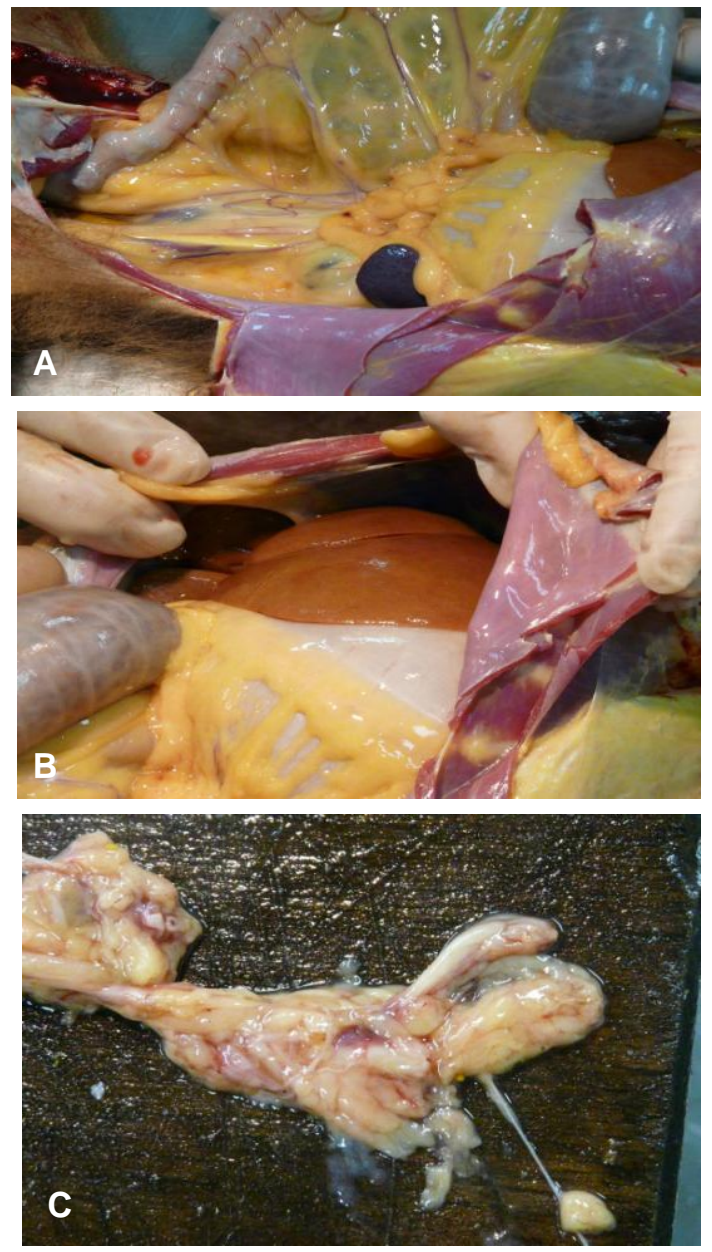

Figura 1. Achados macroscópicos de necropsia de um exemplar macho adulto de bugio-ruivo (Alouatta guariba clamitans) compatíveis com pancreatite aguda necrótica. A) acentuado grau de icterícia em ligamento mesentério e omento maior e menor; B) coloração marrom-pálida de fígado com hepatomegalia; C) destruição de grande parcela do tecido acinar pancreático, áreas de coloração amarelo-acinzentada.

Conclui-se que o quadro de pancreatite aguda necrótica resultou em óbito do animal. A icterícia e o aumento nas atividades séricas das enzimas hepáticas foram compatíveis com o quadro de pancreatite. As alterações laboratoriais e os achados macroscópicos à necropsia foram essenciais para a caracterização do quadro. Em virtude da manutenção do animal em cativeiro, acredita-se que a causa provável da doença tenha sido manejo nutricional inadequado por longo período.

Palavras-chave: primata, pâncreas, hematologia, bioquímica, icterícia 


\begin{abstract}
This paper reports the development of necrotic acute pancreatitis in a captive male adult Southern Brown Howler Monkey (Alouatta guariba clamitans, Cabrera, 1940) presenting acute apathy and anorexia. Blood samples were collected and supportive treatment was made although death could not be avoided. Necropsy was performed. First erythrogram results showed polycythaemia due to dehydration; second exam revealed anemia after fluid administration. Leukopenia with neutropenia suggested poor prognosis. Creatinine was in the reference range although BUN (blood urea nitrogen) was increased. Increased alanine aminotransferase, aspartate aminotransferase and creatin kinase serum activities were observed. Amylase and lipase serum activities were incredibly high. Necropsy revealed intense icterus in subcutaneous tissue and internal structures, including misshapen pancreas with rare glandular tissue. Acute pancreatitis diagnosis was made by clinical signs, laboratory findings, and necropsy.
\end{abstract}

Keywords: primate, pancreas, hematology, biochemistry, icterus

\section{REFERÊNCIAS BIBLIOGRÁFICAS}

ANDRADE, S.F.; CAMARGO, P.L.; VIANNA, L.C. et al. Terapêutica do sistema digestivo. In: ANDRADE, S.F. (Ed). Manual de terapêutica veterinária. 2.ed. São Paulo: Roca, 2002. Cap.12, p.223-263.

BREAZILE, J.E. Physiologic basis and consequences of distress in animals. J. Am. Vet. Med. Assoc., v.191, p.1212-1215, 1987.

CARNEIRO, M.C.; SIQUEIRA-BATISTA, R. O mosaico patogênico da pancreatite aguda grave. Rev. Col. Bras. Cirurg., v.31, p.391-397, 2004.

FRASER, C.M. Manual Merck de veterinária. 7.ed. São Paulo: Roca, 1997. Cap.2, p.110-305.

HIRSCH, A. Estudo comparativo das espécies do gênero Alouatta Lacépède, 1799 (Platyrrhini, Cebidae) e sua distribuição geográfica. 1988. 90f. Monografia (Bacharelado) - Universidade Federal do Rio Grande do Sul, Porto Alegre.
MOORE, F.M.; BENDER, H.S. Neutropenia. In: FELDMAN, B.F.; ZINKL, J.G.; JAIN, N.C. Schalm's veterinary hematology. 5.ed. Philadelphia: Lippincott Williams \& Wilkins, 2000. Cap.53, p.350-355.

SANTOS, L.C. Laboratório ambiental. Cascavel: Edunioeste, 1999. Cap.12, p.233-305.

SILVA JÚNIOR, E.C.A. Preliminary survey of brown howler monkeys (Alouatta fusca) at the Cantareira reserve (São Paulo, Brazil). Rev. Bras. Biol., v.41, 897-909. 1981.

STUART, D.M.; PENDERGAST, V.; RUMFELT, S. et al. Parasites of wild howlers (Alouatta spp.). Int. J. Primatol., v.19, p.493512, 1998.

TEARE, J.A. (Ed). Physiological data reference values. Apple Valley, MN: International Species Information System (ISIS), 1999.

THRALL, M.A. Hematologia e bioquímica clínica veterinária. São Paulo: Roca, 2007. 582p. 